\title{
Das Staatsbürgerschaftsrecht Südafrikas unter besonderer Berücksichtigung der ehemaligen Homelands
}

\author{
Von Wolf B. van Lengerich, Frankfurt/Main
}

\section{Einleitung}

$\mathrm{Zu}$ Beginn der neunziger Jahre des letzten Jahrhunderts konnten weltweit Veränderungen der staatlichen und politischen Systeme verzeichnet werden. Die ehemaligen Ostblockstaaten, die von dieser Entwicklung am stärksten betroffen waren, veränderten mit der Abkehr vom Kommunismus weitgehend ihr Gesicht. Diese nahezu revolutionäre Entwicklung machte auch vor Südafrika nicht halt. In den letzten Jahren des alten Jahrtausends vollzog sich in dem Land am Kap der guten Hoffnung eine solch grundlegende Veränderung des Staats- und Rechtssystems, wie sie einschneidender für die positive Entwicklung der Menschen- und Freiheitsrechte kaum hätte sein können. ${ }^{1}$ Das Land, drangsaliert von einer dreihundertjährigen Unterdrückung der schwarzen Mehrheit und der rigorosen Durchsetzung der Vormachtstellung einer weißen Minderheit, gab sich nach drei Jahren des friedlichen Ringens am 27. April 1994 eine Verfassung, die nunmehr sämtliche staatlichen Organe bindet. Zum ersten Mal in der Geschichte des Landes stehen alle Menschen gleichberechtigt nebeneinander. Die politischen Rechte, die bis zu diesem Zeitpunkt nur von der regierenden weißen Minderheit ausgeübt worden waren, gelten jetzt für alle südafrikanischen Bürger, so daß zu den ersten gemeinsamen und freien Wahlen, ebenfalls am 27. April 1994, die gesamte südafrikanische Bevölkerung aufgerufen worden war. Mit der Abkehr vom früheren Rechtssystem war auch die Auflösung des zentralistischen Staates verbunden. Es wurde statt dessen ein föderalistischer Bundesstaat geschaffen, der aus acht Provinzen besteht, die, ähnlich dem deutschen System, umfassende Selbstverwaltungsaufgaben wahr-

Mahomed, Stellvertretender Präsident des Verfassungsgerichts in: AZAPO v President of the Republic of South Africa, 1996 (4) SA 671 (CC), Rz. 1: „Für Jahrzehnte wurde die Geschichte Südafrikas dominiert von einem tiefen Konflikt zwischen einer Minderheit, die für sich die Kontrolle über sämtliche politischen Instrumente in Anspruch nahm, und einer Mehrheit, die versuchte diese Beherrschung abzuschütteln. [...] Das Resultat waren entkräftende politische Konfrontationen, massive militante Arbeiteraufstände, Studentenunruhen, internationale wirtschaftliche Isolation, Umsiedlung vieler Gruppen in weit auseinander liegende Gebiete, Vermehrung von militärischen Einsätzen und eine gefährliche Kombination einer ängstlichen, frustrierten und enttäuschten immer größer werdenden Bevölkerungsmehrheit. Die Legitimität von Recht und Gesetz war tief getroffen und der tragische Konflikt begann, das gesamte Land zu traumatisieren." 
nehmen. Das ehemals geltende Westminster-Modell wurde ebenfalls abgeschafft und durch die Verhältnismäßigkeitswahl ersetzt. ${ }^{2}$

Die Jahrzehnte bis zur politischen Wende der neunziger Jahre waren bestimmt durch eine Politik der Rassentrennung. Wichtigste Strategie zur Durchsetzung dieser Apartheidspolitik war die Gründung der sogenannten Homelands. Dies waren eigenständige und unter Selbstverwaltung stehende Territorien, die von Südafrika, im Gegensatz zur internationalen Staatengemeinschaft, als nahezu selbständige Staaten betrachtet wurden. Ziel der südafrikanischen Politik war es, die schwarze Bevölkerungsmehrheit aus Südafrika auszubürgern und in den künstlich geschaffenen Homelands anzusiedeln, um diese fortan nicht mehr als Südafrikaner ansehen zu müssen. Mit der Abschaffung des Apartheidsystems und der darauf ausgerichteten Politik wurden die vier selbstverwalteten Homelands Transkei, Bophuthatswana, Venda und Ciskei (im folgenden TBVC-Staaten) in den Jahren nach der Wende wieder mit dem südafrikanischen Staat vereint. Hieraus resultierte eine Vielzahl staatsbürgerlicher Probleme. Es sollten all diejenigen, die die südafrikanische Staatsbürgerschaft bereits einmal besessen und sie durch die Ausbürgerung und Umsiedlung in die Homelands verloren hatten, wieder südafrikanische Staatsbürger werden. Daneben sollten auch deren Nachkommen einen südafrikanischen $\mathrm{Pa}$ erhalten. Gleichzeitig hatten sich die Homelands aber auch zur Zufluchtsstätte für eine Vielzahl von Menschen entwickelt, die nicht aus Südafrika ausgebürgert worden waren, sondern aus anderen afrikanischen Staaten stammten. Darüber hinaus hatte sich Südafrika nach der Wende zu Beginn der neunziger Jahre zu einer Zufluchtsstätte nicht nur für politische, sondern auch für wirtschaftliche Flüchtlinge entwickelt. ${ }^{3}$ Die zu Beginn der Regierungszeit des $\mathrm{ANC}^{4}$ noch offene Haltung der südafrikanischen Regierung gegenüber einwandernden Ausländern wechselte schon bald in eine Politik der Zurückhaltung, da sich Südafrikas neue Regierung mit einer großen Zahl von Immigranten aus wirtschaftlich schwächeren Anrainerstaaten konfrontiert sah, die nicht nur von der wesentlich besseren Arbeitssituation, sondern auch von der sichereren Menschenrechtslage profitieren wollten. Südafrika ging in der Folgezeit zu einer restriktiveren Einwanderungspolitik über, so daß sich viele Menschen in den Gebieten der 1994 wieder eingegliederten Homelands niederließen, um dann über die noch bis 1995 bestehende Staatsbürgerschaft der TBVC-Staaten die südafrikanischen Staatsbürgerschaft zu erlangen. $\mathrm{Zu}$ den dargelegten Problemen kam hinzu, daß parallel zur neuen Verfassung,

3 L. Hill / H. Kotzé, South Africa in Southern Africa: The Politics of Migration and Citizenship, 1998, Annual Meeting of the American Political Science Association, http://www.sun.ac.za/local/ academic.arts/polwet/polwet.htm, S. 2.

4

African National Congress; seit 1994 regierende Partei in Südafrika. 
die die Grundsätze der Menschenrechte proklamierte, noch die von der Apartheidspolitik geprägten Staatsbürgerschafts- und Einwanderungsgesetze fortbestanden. ${ }^{5}$

Fokussiert werden soll die Entwicklung des südafrikanischen Staatsbürgerschaftsrechts. Ausgangspunkt ist das apartheidspolitische System Südafrikas und das damit verbundene Staatsbürgerschaftsrecht. Die Abkehr von diesem System und dem damit verbundenen auf Rassentrennung ausgerichteten Staatsbürgerschaftsrechts begann mit dem Einfluß des internationalen Völkerrechts und dem Beitritt Südafrikas zu mehreren internationalen Menschenrechtskonventionen. Entscheidend ist die Neugestaltung des Staatsbürgerschaftsrechts ist jedoch von der 1994 geschaffenen Verfassung und den darin enthaltenden Freiheits- und Menschenrechten geprägt worden. Mit dem Erlaß des South African Citizenship Act von 1995 wurde ein Gesetz zur Staatsbürgerschaft erlassen, das die Verfassungsrechte umsetzen sollte und das die politische Wende insbesondere in Bezug auf die Vergabe der südafrikanischen Staatsbürgerschaft vorerst beendete.

\section{Südafrikas Staatsbürgerschaftsrecht von 1949 bis 1995}

Mit Abschluß der Commonwealth Konferenz von 1947 trennte sich Südafrika von dem die Commonwealthstaaten beeinflussenden britischen Staatbürgerschaftssystem. Das Land am Kap gab sich 1949 ein eigenes Staatsbürgerschaftsgesetz, den South African Citizenship Act (im folgenden SACA 49). ${ }^{6}$ Das Gesetz regelte die Möglichkeiten des Erwerbs der Staatsbürgerschaft und deren Verlust. Danach konnte die südafrikanische Staatsbürgerschaft sowohl durch Geburt und Abstammung, als auch durch Einbürgerung und im Einzelfall bis 1962 auch durch einfache Registrierung erworben werden. In den Jahren nach 1949 war die Gesetzesauslegung stark an die politische Ausprägung des Apartheidsystems gebunden. Oftmals erneuert, ${ }^{7}$ wurde der SACA 49 so ausgelegt, daß Rassentrennung und Ausbürgerung vieler schwarzer Südafrikaner gesetzeskonform erfolgen konnte. ${ }^{8}$

J. Klaaren, So far not so good: An Analysis of Immigration Decisions under the Interim Constitution, SAJHR, 1996, Vol. 12, S. 605.

6 South African Citizenship Act 44 aus 1949.

7 Der SACA 49 wurde durch die SA Citizenship Amendments Acts von 1961, 1973, 1978, 1980, 1981, 1984 und 1991 verändert.

8

J. Klaaren, Immigration and the South African Constitution, in: J. Crush, Beyond Control: Immigration and Human Rights in a democratic South Africa, 1998, S. 55, 57. 
Der Erwerb der südafrikanischen Staatsbürgerschaft beruhte auf dem ius soli. Aufgrund seiner Geburt in Südafrika hatte zwischen 1949 und 1995 jeder ein Anrecht darauf, die südafrikanische Staatsbürgerschaft zu erwerben. ${ }^{9}$ Das Gesetz sah von diesem Grundsatz folgende Ausnahmen vor: Die Erteilung der Staatsbürgerschaft wurde demjenigen verwehrt, dessen Vater ein illegaler Einwanderer, ein ausländischer Diplomat oder jemand war, der aus anderen Gründen keinen Anspruch auf eine Daueraufenthaltsgenehmigung hatte. ${ }^{10}$ Ein Anspruch zum Erwerb der südafrikanischen Staatsbürgerschaft bestand ebenfalls nicht für diejenigen, die außerhalb des Staates geboren worden waren. Die Staatsbürgerschaft konnte jedoch in diesem Fall aufgrund des ius sanguinis erworben werden, wenn der Vater oder die Mutter des Antragstellers südafrikanischer Staatsbürger war. ${ }^{11}$

1961 erklärte sich Südafrika zur Republik und wurde damit gänzlich unabhängig von der Vereinigung der Commonwealthstaaten. ${ }^{12}$ Diejenigen, die bereits im Land lebten und Bürger eines Commonwealthstaates oder Irlands waren, bzw. mit einem Südafrikaner verheiratet oder minderjährig waren, konnten sich bis Juni 1962 für die südafrikanische Staatsbürgerschaft registrieren lassen. Die Registrierung war eine vereinfachte Form der Einbürgerung und lag im Ermessen des Innenministers. ${ }^{13}$

Einwanderern stand der Weg zur Staatsbürgerschaft auch über das Einbürgerungsverfahren offen. Hieran waren zahlreiche Voraussetzungen geknüpft, wobei die endgültige Entscheidung über die Einbürgerung im Ermessen des Innenministers stand. ${ }^{14}$ Dem Antragsteller oblag es, nachzuweisen, daß er bereits aufgrund einer Daueraufenthaltsgenehmigung in Südafrika lebte und sich zumindest während vier der acht Jahre, die das Verfahren dauerte, im Land aufgehalten hatte. Er mußte von gutem Charakter sein, eine der Nationalsprachen, Englisch oder Afrikaans, sprechen und darlegen, daß er es anstrebe, weiterhin dauerhaft in Südafrika zu leben. Die Entscheidung über den Antrag, die der Minister traf, konnte ohne Angabe von Gründen erfolgen. Diese Entscheidung war endgültig und unterlag keinem Rechtsmittel. $^{15}$

9

10

11

12

13

14

15

§ 3 Abs. 1 SACA 49.

$\S 3$ Abs. 2 SACA 49.

$\S 4$ SACA 49.

C. W. H. Schmidt, in W. A. Joubert: The Law of South Africa, 1993, Vol. 2, S. 219.

$\S 8$ Abs. 10 SACA 49.

$\S 11$ SACA 49.

$\S 11$ Abs. 14 SACA 49; C. W. H. Schmidt, in W. A. Joubert: The Law of South Africa, 1993, Vol.

2, S. 222. 
Neben dem Erwerb regelte der SACA 49 auch den Entzug der Staatsbürgerschaft. Ein solcher sollte erfolgen, wenn die Einbürgerung aufgrund falscher Angaben zur Person oder andersartigem Betrug erfolgt war. ${ }^{16}$ Ferner wenn der Bürger sich in einem anderen Land treulos gegenüber dem südafrikanischen Staat verhalten hatte. Dies wurde z.B. angenommen, wenn ein Bürger mit doppelter Staatsbürgerschaft in der Armee eines anderen Landes gedient hatte. Ein weiterer Entziehungsgrund bestand in der Verurteilung wegen Hochverrats, der Verurteilung zu mehr als 12 Monaten Haft oder einer Geldstrafe von 200 Rand innerhalb der ersten fünf Jahre nach der Einbürgerung. ${ }^{17}$ Als Entziehungsgrund galt auch die Annahme der Staatsbürgerschaft eines anderen Landes. ${ }^{18}$ Es stand im Ermessen des Ministers zu entscheiden, ob durch die Annahme einer anderen Staatsbürgerschaft, die nicht aufgrund einer Heirat erfolgt war, ein öffentliches Interesse an der Entziehung der südafrikanischen Staatsbürgerschaft bestand. ${ }^{19}$

\section{b) Homelandpolitik}

Seit Beginn der zweiten Hälfte des zwanzigsten Jahrhunderts bestimmte das Ziel der Rassentrennung immer stärker die Politik Südafrikas. Inhalt der Apartheidspolitik war die endgültige Ausgliederung der schwarzen Bevölkerungsteile aus der Republik Südafrika und die Sicherung der Vormachtstellung der weißen Minderheit im Land. Der schwarze Bevölkerungsteil sollte zu diesem Zweck in eigenständig verwaltete Homelands umgesiedelt werden, die wirtschaftlich von Südafrika abhängig sein sollten. Die Trennung der Homelands vom Mutterland ging dabei Hand in Hand mit der Entziehung der südafrikanischen Staatsbürgerschaft. ${ }^{20}$ Da die internationale Staatengemeinschaft die Gründung der Homelands als eigenständige Staaten nicht anerkannte und die Bevölkerung der Homelands nicht staatenlos sein konnte, wurde formal zwischen Nationalität und Staatsbürgerschaft unterschieden. Nationalität (Staatsangehörigkeit) ist ein Begriff des internationalen Rechts, der besagt, daß es eine rechtliche Verbindung zwischen einer Person und einem Staat gibt, die bei der Durchsetzung außerstaatlicher Interessen dieser Person entscheidend ist. Ein Südafrikaner konnte demnach, soweit er einen $\mathrm{Pa}$ besaß, mit diesem reisen und war berechtigt, den südafrikanischen Staat um Beistand gegenüber einem anderen Staat anzurufen, falls er dort in rechtliche Schwierigkeiten geriet. ${ }^{21}$ Staatsbürgerschaft ist dagegen ein verfassungs-

16

17

18

19

20

21

$\S 19$ Abs. 2 SACA 49.

$\S 15$ Abs. 1 b); $§ 19$ Abs. 3 a), b), d) SACA 49.

$\S 19$ Abs. 1 a) (i)(ii) SACA 49.

C. W. H. Schmidt, in W. A. Joubert: The Law of South Africa, 1993, Vol. 2, S. 226.

J. Dugard, International Law - A South African Perspective, 1994, S 174.

Nach südafrikanischem Recht hatte jemand, der nur unter die Definition der Nationalität des Landes fällt, keinen Anspruch auf einen Paß. Sowohl die Erteilung als auch die Entziehung des Passes stand im Ermessen der Verwaltung. Sachs v Dönges NO 1950 (2) SA 265 (A); Tutu v 
rechtlicher Begriff. Er beschreibt ein staatsinternes Recht des Bürgers gegenüber dem Staat und seinen Anspruch auf Ausübung der politischen Rechte. ${ }^{22}$ Mit der Trennung der Homelands von der Republik Südafrika verloren die in den TBVC-Staaten lebenden schwarzen Bevölkerungsteile ihre südafrikanische Staatsbürgerschaft. Infolgedessen hatten sie weder politische Rechte in Südafrika, noch hatten sie einen Anspruch auf Ausstellung eines südafrikanischen Passes. Um dennoch ins Ausland reisen zu können, konnte das südafrikanische Innenministerium den Bürgern der Homelands einen südafrikanischen $\mathrm{Pa} ß$ ausstellen. Dessen Ausstellung war jedoch eine Ausnahme, die im Ermessen des Innenministers stand. Hinsichtlich der weitergehenden internationalen Belange standen die Bürger der Homelands, denen ein $\mathrm{Pa} ß$ ausgestellt worden war, dann jedoch unter dem Schutz der südafrikanischen Republik. ${ }^{23}$

Die Gründungsphase der Homelands und die damit verbundene Bildung einer selbständigen Verwaltung begann 1963 mit dem Transkei Constitution Act. Dieses Gesetz sah eine neue Art der südafrikanischen Staatsbürgerschaft vor. Danach sollten Bewohner eines bestimmten Gebietes innerhalb der Republik besondere Rechte und Pflichten erhalten. Ihnen sollte die Möglichkeit offen stehen, eine für das Gebiet zuständige Verwaltung zu wählen oder sich selbst zur Wahl zu stellen. Gleichzeitig sollten sie ihre Einkommenssteuer in einen gebietsinternen Fonds zahlen. Die Bewohner dieser Gebiete behielten jedoch die südafrikanische Staatsbürgerschaft bei. Mit dem Bantu Homeland Citizenship Act von 1970 ging diese Phase zu Ende. Durch dieses Gesetz, das eine Generalvorschrift für die Verteilung der schwarzen Staatsbürger auf die verschiedenen Homelands enthielt, wurden die TBVC-Staaten endgültig in ihre Unabhängigkeit entlassen. ${ }^{24}$ Die Verteilung der schwarzen Bevölkerungsgruppen auf die Homelands richtete sich nach dem Geburtsort in einem Homeland, dem Wohnort in einem Homeland für mehr als fünf Jahre, der Sprache oder der kulturellen Gleichheit mit den Bewohnern eines Homelands. Diese Kriterien wurden in die jeweiligen Unabhängigkeitsgesetze der Homelands übernommen. ${ }^{25}$ Das südafrikanische Parlament verabschiedete die Unabhängigkeitsgesetze für die Transkei 1976, für Bophuthatswana 1977, für Venda 1979 und für Ciskei $1981 .^{26}$ Mit dem Inkrafttreten der Unabhängigkeitsgesetze verloren die Bewohner der Homelands endgültig die südafrikanische Staatsbürgerschaft. Aufgrund dieses Verlustes wurden diejenigen, die

Minister of Internal Affairs 1982 (4) SA 571 (T); Boesak v Minister of Home Affairs 1987 (3) SA 665 (C); C. W. van Wyk, The South African Passport, SAYIL, 1976, Vol. 2, S. 212.

Tshwete v Minister of Home Affairs (RSA) 1988 (4) SA 586, 614 E f.

J. Dugard, International Law - A South African Perspective, 1994, S. 173 und S. 179.

Bantu Homeland Citizenship Act 26 von 1970, der Begriff „Bantu“ steht dabei für „Schwarzer“. Er wurde 1978 durch den Plural Relations and Development Act durch „Black“ ersetzt.

Schedule B der Status Acts, s. Fn. 24.

26

Transkei Status Act 100, von 1976; Bophuthatswana Status Act 89 von 1977; Venda Status Act 107 von 1979 und Ciskei Status Act 110 von 1981. 
durch Umsiedlung und Eingliederung Bürger der Homelands geworden waren, Ausländer in Südafrika. Die Behandlung und die Ausweisung von Ausländern war wiederum gesetzlich geregelt. Aufgrund des Aliens Control Acts ${ }^{27}$ war der Innenminister berechtigt, nach seinem Ermessen zu bestimmen, in welchem Fall die Inhaftierung und Ausweisung einer Person, die nicht die südafrikanische Staatsbürgerschaft besaß, im öffentlichen Interesse stand. Da ein Rechtsmittel gegen die Entscheidung des Ministers nicht möglich war, stand der Durchsetzung der Apartheidspolitik nichts mehr im Wege. ${ }^{28}$ Die Entscheidungen der südafrikanischen Gerichte beschränkten sich in diesem Zusammenhang ausschließlich auf die Feststellung, daß es allein dem südafrikanischen Staat oblag, über den Einlaß und die Ausweisung von Personen zu entscheiden. ${ }^{29}$

In der Folgezeit wurden zahllose Menschen in die Homelands umgesiedelt. Da jedoch Industrie und Farmen nicht auf die Arbeitskräfte, die sich zum größten Teil aus der schwarzen Bevölkerung rekrutierten, verzichten konnten, wurden Sondergenehmigungen für Arbeiter zur Ansiedlung in sogenannten Townships nahe den Städten und Industriestandorten eingeführt. ${ }^{30}$ Die Arbeiter weigerten sich jedoch oftmals infolge schlechter Lebensbedingungen in den vorgeschriebenen Townships zu siedeln, oder aber sie holten entgegen den Vorschriften ihre Familien aus den Homelands nach. Die Folge dieser Siedlungspolitik waren ständige Auseinandersetzungen und Unruhen zwischen Vollzugsbehörden und Arbeitern. $^{31}$

Aufgrund der immer lauter werdenden Kritik aus dem Ausland zu Beginn der achtziger Jahre, die nicht nur das Apartheidregime in Südafrika verurteilte, sondern auch internationale Investoren veranlaßte, ihr Kapital dem Land zu entziehen, sollte eine Änderung der Politik der Rassentrennung durch ein neues Staatsbürgerschaftsgesetz eingeleitet werden. ${ }^{32}$

$\S 47$ Aliens Control Act 96 von 1991 (vormalig § 45 Admission of Persons to the Republic Regulation Act 59 von 1992.

J. Dugard, International Law - A South African Perspective, 1994, S 183.

29

Lewis v Minister of Internal Affairs 1991 (3) SA, S. 628 (B); Tshwete v Minister of Home Affairs 1986 (2) SA S. 240 (E), 243 G f.; Maluleke v Minister of Internal Affairs 1981 (1) SA, S. 707 (B), 713.

$\S 10$ Native (Urban Areas) Consolidation Act.

31

B. J. Anderson, The Restoration of the South African Citizenship Act: An Exercise in Statutory Obfuscation, Connecticut JIL, 1994, Vol. 9, Nr. 2, S. 309; G. Budlender, Incorporation and Exclusion: Recent Developments in Labour Law and Influx Control, SAYHR, 1985, Vol. 1, S. 6.

J. L. Redleaf, The Division of Foreign Policy Authority Between the European Community and the Member States: A Survey of Economics Sanctions Against South Africa, 12 B. C., Third World LJ, 1992, S. 97; T. M. Corsi, EEC Sanctions Against South Africa: The Common Com- 
Hierzu verabschiedete die südafrikanische Regierung 1986 den Restoration of South African Citizenship Act. ${ }^{33}$ Das Gesetz sah vor, daß Bürgern der Homelands die südafrikanische Staatsbürgerschaft durch Geburt, Abstammung, Registrierung oder Einbürgerung verliehen werden sollte. Diese im internationalen Vergleich normal erscheinende Vergabe der Staatsbürgerschaft war jedoch an zahlreiche Voraussetzungen geknüpft, die es letztlich nur 1,8 Millionen der 9 Millionen Homelandbürgern ermöglichten, die südafrikanische Staatsbürgerschaft zu erhalten. ${ }^{34}$

Die Bürger der TBVC-Staaten konnten die südafrikanische Staatsbürgerschaft durch Geburt erlangen, wenn sie bereits vor der Unabhängigkeit der Homelands, durch die sie die südafrikanische Staatsbürgerschaft verloren hatten, in Südafrika geboren worden waren. Sie mußten dauerhaft in der Republik Südafrika in der Zeit vor dem 1. Juli 1986 gelebt haben und ein Gesuch an den Innenminister gerichtet haben. Eine ungeschriebene Voraussetzung bestand außerdem darin, daß die Antragsteller eine Daueraufenthaltsgenehmigung für Südafrika besessen haben mußten. Solche waren jedoch auf der Grundlage von $\S 10$ Native (Urban Areas) Consolidation Act nur denjenigen erteilt worden, die durchgehend für einen Zeitraum von mehr als zehn Jahren für einen Arbeitgeber gearbeitet hatten. ${ }^{35}$ Davon betroffen waren in der Praxis regelmäßig nur Männer, die in der Landwirtschaft oder der Minenindustrie gearbeitet hatten. Frauen und Kinder wurden dagegen nur selten als Arbeitskräfte eingestellt. Aber auch Arbeiter hatten nur selten eine Daueraufenthaltsgenehmigung erhalten, da sie selten länger als zehn Jahre in dem gleichen Unternehmen gearbeitet hatten. ${ }^{36}$ Einen direkten Anspruch auf die südafrikanische Staatsbürgerschaft hatten infolge ihrer Geburt dagegen diejenigen, die in der kurzen Zeitspanne zwischen der Unabhängigkeit der Homelands und ihrer Wiedereingliederung in der Republik Südafrika geboren worden waren und seitdem dort gelebt hatten. ${ }^{37}$

Die Erlangung der südafrikanischen Staatsbürgerschaft aufgrund von Abstammung war an noch weitergehende Voraussetzungen geknüpft. Die Antragsteller mußten minderjährige Kinder von Eltern sein, die die Staatsbürgerschaft durch Geburt erlangt hatten. ${ }^{38}$ Die Kin-

mercial Policy and the Delimitation of the EEC's Powers, International and Comparative LR, 1987, S. 119; J. F. Grey, The Passage of the Federal Anti-Apartheid Act: The Culmination of Anti-Apartheid Efforts Within the U.S., Suffolk Transnational LJ, 1988, Vol. 11, S. 387.

C. W. H. Schmidt, in W. A. Joubert: The Law of South Africa, 1993, Vol. 2, S. 257.

J. Klaaren, Post Apartheid Citizenship in South Africa, 1999, http://www.law.wits.ac.za/school/ klaaren/klaarenc.htm, S. 3, s. auch Carnegie International Migration Policy Program.

B. J. Anderson, The Restoration of the South African Citizenship Act: An Exercise in Statutory Obfuscation, Connecticut JIL, 1994, Vol. 9, Nr. 2, S. 310.

Ibid.

$\S 2$ Restoration of South African Citizenship Act 73 von 1986.

$\S 3$ Restoration of South African Citizenship Act. 
der mußten darüber hinaus außerhalb der Republik geboren worden sein und zwar in der Zeit nach der Unabhängigkeit des Homelands. Außerdem war der Besitz einer Daueraufenthaltsgenehmigung für die Zeit vor Inkrafttreten des Restoration Acts am 1. Juli 1986 erforderlich. ${ }^{39}$ Die Zahl derer, die unter diese Voraussetzungen fielen, war äußerst gering. Denn es ergab sich nur selten die Konstellation, daß den Eltern eines Antragstellers, der außerhalb von Südafrika geboren worden war, die Staatsbürgerschaft aufgrund ihres Geburtsortes verliehen worden war, da dies wiederum von einem dauerhaften Aufenthalt in Südafrika abhing. ${ }^{40}$

Eine weitere Möglichkeit der Einbürgerung bestand in der Registrierung, die im Ermessen des Innenministers stand. Die Registrierung war an die Voraussetzung geknüpft, daß die Antragsteller südafrikanische Staatsbürger gewesen sein mußten und die Staatsbürgerschaft aufgrund der Unabhängigkeit des Homelands, in das sie umgesiedelt worden waren, verloren hatten. ${ }^{41}$ Die Antragsteller mußten in dem acht Jahre dauernden Einbürgerungsverfahren nachweisen, daß sie eine Daueraufenthaltsgenehmigung für die Republik Südafrika besaßen, die für mindestens vier der acht Jahre der Einbürgerungszeit gegolten haben mußte. Auch in diesem Verfahren stellten sich den Schwarzen die schwer zu erfüllenden Voraussetzungen für den Erhalt einer Daueraufenthaltsgenehmigung in den Weg. ${ }^{42}$

Schließlich konnte die Staatsbürgerschaft durch Einbürgerung erlangt werden. ${ }^{43}$ Dazu mußten die Antragsteller oder ein Elternteil vor der Unabhängigkeit der Homelands in einem Teil Südafrikas geboren worden sein, der der weißen Bevölkerung vorbehalten gewesen war, und sie mußten nach 1986 die Republik entsprechend den Einwanderungsvorschriften betreten haben. Eine andere Möglichkeit der Einbürgerung für weibliche Antragsteller bestand darin, daß sie nachwiesen, mehr als zwei Jahre mit einem Südafrikaner verheiratet gewesen zu sein. Die Einbürgerung stand, wie die Registrierung, im Ermessen des Innenministers und war abhängig von der vorgegebenen Regierungspolitik, die nach 1986 weiterhin durch die Apartheid geprägt war. ${ }^{44}$ Da der Restoration of South African Citizenship Act keine weitergehende Öffnung gegenüber den TBVC-Staaten mit sich brachte und ein Ende der Rassentrennung durch die Spaltung des Landes nicht in Sicht

39

40

41

42

43

44

B. J. Anderson, The Restoration of the South African Citizenship Act: An Exercise in Statutory Obfuscation, Connecticut JIL, 1994, Vol. 9, No. 2, S. 321; G.Budlender, On Citizenship and Resident Rights: Taking Words Seriously, SAJHR, 1989, Vol. 5, S. 52. 
war, richteten sich die internationalen Proteste weiter gegen die südafrikanische Regierung und ihre Diskriminierung der schwarzen Bevölkerung.

\section{Einfluß des internationalen Rechts}

Das Recht zur Erteilung der Staatsbürgerschaft eines Landes steht in unmittelbarem Zusammenhang mit dem Recht des Staates, die Staatsbürgerschaft zu entziehen. Wie viele andere Staaten hat auch Südafrika dieses Recht in seinen Gesetzen verankert. Aufgrund des South African Citizenship Act von 1949 konnte derjenige die südafrikanische Staatsbürgerschaft verlieren, der eine andere Staatsbürgerschaft annahm, ${ }^{45}$ in einer Armee eines gegenüber Südafrika feindlich eingestellten Landes diente ${ }^{46}$ oder wegen Hochverrats verurteilt worden war. ${ }^{47}$ Das Recht, die Staatsbürgerschaft zu entziehen, unterlag den gesetzlichen Voraussetzungen und stand im Ermessen des Innenministers. Dieser Ermessensspielraum, der nur rechtmäßig ausgeübt wurde, wenn die notwendige Abwägung innerhalb der Grenzen der nationalen Gesetze erfolgte, unterlag dem internationalen Recht, insbesondere internationalen Abkommen und internationalem Gewohnheitsrecht. Es beinhaltet Vorschriften, die festlegen, welche Gründe nicht zu einer Entziehung der Staatsbürgerschaft führen dürfen. ${ }^{48}$ Art. 15 der Universal Declaration of Human Rights besagt im Einklang mit Völkergewohnheitsrecht, daß niemandem willkürlich seine Staatsbürgerschaft und seine Staatsangehörigkeit entzogen werden darf. Art. 9 der Convention on the Reduction of Statelessness von 1961 verbietet die Entziehung der Staatsbürgerschaft aufgrund von Rasse, Ethnie, Religion oder aus politischen Gründen. Art. 5 Abs. d) (iii) der International Convention on the Elimination of All Forms of Racial Discrimination bestimmt, daß ein Staat alle Menschen unabhängig von ihrer Rasse rechtlich gleich behandeln muß. Auf der Grundlage dieser Abkommen wurde Südafrika international für die Entziehung der Staatsbürgerschaft von 9 Millionen schwarzen Südafrikanern und deren Zwangsumsiedlung in die TBVC-Staaten kritisiert. Wegen dieser gegen international anerkannte Menschenrechte verstoßenden Ausbürgerungen erkannte die internationale Staatengemeinschaft die TBVCStaaten nicht als eigene Staaten an.

1985 ratifizierte die südafrikanische Generalversammlung die Declaration on the Human Rights of Individuals Who Are Not Nationals of the Country in Which They Live. Die

45

46

47

48

49
$\S 15$ Abs. 1 a) SACA 49.

$\S 15$ Abs. 1 b) SACA 49.

\$ 19 Abs. 3 SACA 49.

J. Dugard, International Law - A South African Perspective, 1994, S. 179; W. Olivier, Statelessness and Transkeian Nationality, SAYIL, 1976, Vol. 2, S. 143, 154.

J. Dugard, Recognition and the United Nations, 1987, S. $107 \mathrm{f}$. 
Deklaration besagt, daß die Menschenrechte, die wiederum in der Universal Declaration on Human Rights und in internationalen Menschenrechtskonventionen festgeschrieben sind, auch für diejenigen Menschen gelten, die nicht die südafrikanische Staatsbürgerschaft besitzen und dennoch in Südafrika leben. ${ }^{50}$ Die in internationalen Instrumenten zum Schutz der Menschen- und Bürgerrechte enthaltenen Rechte wurden folglich auch von der Republik Südafrika anerkannt, jedoch nicht umgesetzt. Auch nach der offiziellen Ratifizierung der Konventionen änderte sich bis Anfang der neunziger Jahre nichts an der Politik der Rassentrennung. 51

\section{Die Wende und die südafrikanische Verfassung}

Die politische Wende in Südafrika und die damit verbundene Abkehr von Rassentrennung und Apartheid begann mit den Verhandlungen zwischen der regierenden National Partei und ihren vormaligen politischen Gegnern, den Parteien der schwarzen Bevölkerung. Eingeleitet wurde die politische Wende mit der Konferenz für ein Demokratisches Südafrika (CODESA) am 20. Dezember 1991 und endete zwei hart durchkämpfte Jahre später mit der Annahme der Interimsverfassung am 22. Dezember 1993. ${ }^{52}$ Auf deren Grundlage wurden am 27. April 1994 die ersten freien Wahlen Südafrikas abgehalten, die ein Parlament und eine Regierung der nationalen Einheit hervorbrachten. Zwar galt die Übergangsverfassung nur vorübergehend, sie nahm jedoch denselben justiziablen Rang wie die endgültige Verfassung ein, von der sie 1996 ablöst wurde. ${ }^{53}$

\section{a) Entstehung der Verfassung und Wiedervereinigung}

Bestandteil der Verhandlungen über die Neugestaltung der politischen und rechtlichen Ordnung Südafrikas war u.a. die Überarbeitung des SACA 49. Zu diesem Zweck wurde 1993 der Restoration and Extension of South African Citizenship Act erlassen. ${ }^{54}$ Dieser gab denjenigen mit sofortiger Wirkung die südafrikanische Staatsbürgerschaft zurück, die sie durch die Unabhängigkeit der TBVC-Staaten verloren hatten. Ferner wurde denjenigen die Staatsbürgerschaft mit sofortiger Wirkung gegeben, die sie aufgrund ihrer Geburt oder Abstammung erhalten hätten, wäre dies nicht durch die Unabhängigkeitsgesetze der

J. Dugard, Recognition and the United Nations, 1987, S. $107 \mathrm{f}$.

51

J. Dugard, International Law - A South African Perspective, 1994, S 185 f.

52

J. de Waal / I. Currie / G. Erasmus, The Bill of Rights Handbook, 1998, S. 4.

53 Certification of the Constitution of the Republic of South Africa 1996, 1996 (4) SA 744 (CC), Rz.

54 13 (First Certification Judgement).

Restoration and Extension of South African Citizenship Act 196 von 1993. 
Homelands verhindert worden. Hierunter fielen z.B. Kinder von Eltern, die ausschließlich die TBVC-Staatsbürgerschaft besaßen. Darüber hinaus sah das Gesetz vor, daß Personen mit einer Homeland-Staatsbürgerschaft ein Einbürgerungsverfahren für Südafrika zu durchlaufen hatten, um dessen Staatsbürgerschaft zu erlangen. ${ }^{55}$

Der Grund für die schnelle Rückführung der TBVC-Bürger in die südafrikanische Staatsbürgerschaft bestand in den bevorstehenden ersten freien Wahlen, an denen die wieder eingebürgerten Homelandbewohner teilnehmen können sollten. Aus diesem Grund wurde das Wirksamwerden des Restoration and Extension of South African Citizenship Act auf den 1. Januar 1994 und damit vor das Inkrafttreten der Verfassung gelegt. ${ }^{56}$ Um auch auf Verfassungsebene das Wahlrecht der Homelandbewohner abzusichern, trat bereits am 9. März 1994 Art. 6 der Übergangsverfassung, der das Wahlrecht auch Nichtsüdafrikanern zugestand, die durch den Restoration and Extension Act zur Wahl berechtigt waren, in Kraft. Die weitergehende Aufhebung der Unabhängigkeitsgesetze der Homelands erfolgte mit Inkrafttreten der Interimsverfassung und den ersten freien Wahlen. Obwohl die Interimsverfassung eine gemeinsame Staatsbürgerschaft vorsah, ${ }^{57}$ blieben die gesetzlichen Bestimmungen zur Staatsbürgerschaft der vormals unabhängigen Homelands weiter in Kraft. Diese, von den Regierungen der TBVC-Staaten erlassenen eigenständigen Gesetze, wurden durch die neue Verfassung nicht widerrufen. Vielmehr bedurfte es des 1995 wiederum erneuerten South African Citizenship Act, um die alten Gesetze aufzuheben und ein einziges für die gesamte Republik Südafrika geltendes Staatbürgerschaftsgesetz zu schaffen.

\section{b) Staatsbürgerliche Verfassungsrechte}

Sowohl in der Interimsverfassung als auch in der endgültigen Verfassung von 1996 wurde festgelegt, daß bestimmte Rechte ausschließlich Staatsbürgern vorbehalten bleiben. Hierunter fallen die politischen Rechte, ${ }^{59}$ die sich aufteilen in das Recht zur freien politischen Meinungsäußerung, das Recht, eine Partei zu gründen und das Recht auf freie unabhängige

§ 3 Restoration and Extension of South African Citizenship Act.

J. Klaaren, Post-Apartheid Citizenship in South Africa, 1999, http://www.law.wits.ac.za/school/ klaaren/klaarenc.htm, S. 4.

Art. 5 I Interimsverfassung: „There shall be a South African Citizenship.“

Dennoch bestehen auch nach 1995 noch starke Strömungen in Richtung der Gesetzgebung der Homelands. In Bangindawo and Others $v$ Head of the Nyanda Regional Authority and Another 1998 (3) SA 262 (TK) übernahm das Gericht, ungeachtet der Bestimmungen in der Verfassung über eine gemeinsame Staatsbürgerschaft, Auslegungen und Interpretationen zur früheren transkeiischen Staatsbürgerschaft.

Art. 19 endg. Verfassung. 
Wahlen sowie das Recht zu wählen und sich wählen zu lassen. Zu den Staatsbürgerschaftsrechten gehört ferner das Recht auf freie Einreise in die Republik und der Anspruch auf einen eigenen $\mathrm{Paß} .{ }^{60}$ Auch das Grundrecht auf Berufsfreiheit ist anders als noch in der Interimsverfassung auf Staatsbürger beschränkt. Nur diesen ist es gestattet, die Wahl und Ausübung ihres Berufes frei zu wählen. ${ }^{61}$ Letztlich dürfen auch nur Staatsbürger Mitglieder des südafrikanischen Parlaments, der Provinzregierung und der Gemeinde- bzw. Stadträte werden. $^{62}$

Vor dem Hintergrund der Geschichte der Rassentrennung und der Apartheid ist das in Art. 8 der Interimsverfassung und Art. 9 der endgültige Verfassung festgeschriebene Gleichheitsrecht das für die südafrikanische Bevölkerung bedeutsamste Grundrecht. Angesichts der Abtrennung der Homelands von der Republik und der Diskriminierung der Nicht-Südafrikaner in der Vergangenheit, wurde die erste Entscheidung des südafrikanischen Verfassungsgerichts zur Gleichberechtigung von Staatsangehörigen und Nicht-Südafrikanern begrüßt. ${ }^{63}$ In der Entscheidung wurde eine Bestimmung des Bildungsministeriums, die eine Einstellung ausländischer Lehrer auf unbefristete Zeit verhinderte, überprüft. Die Beschwerdeführer hatten gegen die Bestimmungen eine unfaire Diskriminierung geltend gemacht. Im Gegensatz zu südafrikanischen Lehrern waren jene nämlich regelmäßig auf die Verlängerung ihrer Arbeitsverträge angewiesen, was aufgrund von Rationalisierungsmaßnahmen der Provinzregierungen so gut wie ausgeschlossen war. Das Verfassungsgericht entschied, daß eine unfaire Diskriminierung der ausländischen Lehrer gegeben war. Zwar ist die Staatsangehörigkeit in der Verfassung nicht als Grund für die Annahme einer unfairen Diskriminierung aufgeführt, ${ }^{64}$ doch nahm das Gericht an, daß es sich bei einer Ungleichbehandlung aufgrund fehlender Staatsangehörigkeit um eine Diskriminierung handele, die mit den in der Verfassung aufgeführten Gründen vergleichbar sei. Die Vergleichbarkeit mit einer unfairen Diskriminierung aufgrund von Rasse, Geschlecht, Religion, etc. wurde angenommen, da es sich auch bei der Staatsangehörigkeit um ein Merkmal handele, das schwer zu verändern sei und einer Person unmittelbar anhafte. Personen, die nicht die südafrikanische Staatsangehörigkeit besäßen, seien eine Minderheit, die des besonderen verfassungsrechtlichen Schutzes bedürften. ${ }^{65}$ Das Verfassungsgericht erörterte, daß zwischen der Erteilung einer unbefristeten Aufenthaltserlaubnis an ausländische Staatsbürger

60

61

62

63

64

65

Art. 21 endg. Verfassung.

Art. 26 Interimsverfassung; Art. 22 endg. Verfassung.

Art. 47 Abs.1, 106 Abs. 1, 158 Abs. 1 endg. Verfassung.

Larbi-Odam v Member of the Executive Council for Education, 1998 (1) SA 745 (CC).

Vgl. Art. 8 Abs. 2 Interimsverfassung; das Verfassungsgericht bezog sich ausschließlich auf die Interimverfassung.

Larbi-Odam v Member of the Executive Council for Education, (Fn. 53)., Rz. 19. Das Verfassungsgericht erinnerte diesbezüglich auch an die schweren Menschenrechtseingriffe, die durch die Ausbürgerung im Zuge der Homelandpolitik erfolgt waren. 
und der Verhinderung ihrer unbefristeten Einstellung in den Staatsdienst ein Widerspruch bestehe, da Ausländern mit einer unbefristeten Aufenthaltsgenehmigung und südafrikanischen Staatsbürgern die gleichen Arbeits- und Aufenthaltsrechte zuständen. Diese Ausführungen treffen nach Auffassung des Verfassungsgerichts grundsätzlich auch auf ausländische Staatsbürger mit einer befristeten Aufenthaltsgenehmigung zu, sofern sie darauf vertrauen durften, daß die Genehmigung wie zuvor verlängert wird. ${ }^{66}$ Die in der zweiten Bestätigungsentscheidung aufgeworfene Frage, ob auch ausländische Staatsbürger, die sich ohne einen gültigen Aufenthaltstitel in Südafrika aufhalten, von dem Gleichheitsrecht Gebrauch machen können, ließ das Verfassungsgericht indessen offen. ${ }^{67}$

Ausdrücklich legen Art. 3 und Art. 20 der endgültigen Verfassung den Inhalt der Staatsbürgerschaft fest. Art. 20 beinhaltet ein Grundrecht, das generell den Entzug der Staatsbürgerschaft untersagt. ${ }^{68}$ Von diesem Verbot sind Ausnahmen nur aufgrund von Gesetzen möglich, die ihrerseits verhältnismäßig im Hinblick auf die Verfassungsrechte sein müssen. ${ }^{69}$ Art. 3 der endgültigen Verfassung stellt eine Staatszielbestimmung dar, die eine gemeinschaftliche Staatsbürgerschaft vorsieht und alle Staatsbürger in ihren Rechten, Privilegien und Pflichten gleichstellt. ${ }^{70}$ Diese Bestimmung ist daher nicht in der Bill of Rights, dem Grundrechtskatalog der Verfassung, sondern im ersten Kapitel der Verfassung aufgeführt. Der Inhalt der Staatszielbestimmung wird vor dem Hintergrund des Rechtsstaatsprinzips interpretiert. Das Verfassungsgericht legt die Bestimmung sehr weit aus. Es wendet Art. 3 über seinen Wortlaut hinaus sowohl auf Staatsbürger der Republik Südafrika, als auch auf solche, die nicht die südafrikanische Staatsbürgerschaft besitzen, an. Ferner leitet es aus der Staatszielbestimmung ab, daß jedermann den Staat zur Durchsetzung seiner Rechte in Anspruch nehmen kann. Der Staat ist somit verpflichtet, Staatsbürgern und Nicht-Staatsbürgern bei der Durchsetzung ihrer Rechte zur Seite zu stehen. ${ }^{71}$ In dem Fall etwa, daß Eigentum eines südafrikanischen Bürgers durch einen anderen Staat konfisziert wird, ist der südafrikanische Staat verpflichtet, seine Bürger bei der Durchsetzung ihrer Rechte im Ausland zu unterstützen. Der Anspruch auf eine solche Unterstützung wird

Ibid., Rz. 44; J. Klaaren, Non-Citizens and Constitutional Equalitiy: Larbi-Odam v MEC for Education (North-West Province), SAJHR, 1997, Vol. 13, S. 286, 294 ff.

Certification of the Amended Text of the Constitution of the Republic of South Africa, 1996, 1997 (2) SA 97 (CC); 1997 (1) BCLR 1 (CC), Rz. 253.

Art. 20 endg. Verfassung: „No citizen may be deprived of citizenship.“

70

Art. 36 endg. Verfassung: „Limitation of Rights“.

Art. 3 endg. Verfassung:

,(1) There is a common South African Citizenship.

(2) All Citizens are -

(a) equally entitled to the rights, privileges and benefits of citizenship,

(b) equally subject to the duties and responsibilities of the citizenship.

(3) National legislation must provide for the acquisition, loss and restoration of citizenship."

De Lange $v$ Smuts NO and others 1998 (7) BCLR 779 (CC), Rz. 33. 
darüber hinaus auch von Art. 33 der endgültigen Verfassung untermauert, der ein Grundrecht auf ermessensfehlerfreies Handeln der Verwaltung beinhaltet. ${ }^{72}$ Ob der südafrikanische Staat allerdings auch im Inland wohnenden Nicht-Staatsbürgern bei der Durchsetzung ihrer Rechte im Ausland behilflich sein muß, wurde bisher nicht entschieden. Für die Bejahung eines solchen Anspruchs spricht jedoch der geschichtliche Hintergrund der Apartheidzeit. Das Verfassungsgericht hat in einer anderen Entscheidung dementsprechend erklärt, daß Bevorzugungen, wie z.B. der diplomatische Schutz einer bestimmten Personengruppe, unterbunden werden sollen. ${ }^{73}$

Ein wesentlicher Grund für das Recht eines Kindes auf einen Namen ergibt sich aus $\S 9$ Abs. 6 Births and Deaths Registration Act von 1992. ${ }^{74}$ Danach soll die Geburt eines Menschen nicht registriert werden, solange er nicht mit einem Vor- und einem Zunamen benannt worden ist. Der Anspruch auf Registrierung, der sich damit aus der Namensgebung ergibt, wird international gestuitzt von Art. 7 der Convention on the Rights of the Child und Art. 24 Abs. 2 des International Covenant on Civil and Political Rights, der die Staaten zur Registrierung von Geburten anhält. ${ }^{75}$ Mit der Registrierung der Geburt eines Kindes erwirbt dieses auf Grundlage des ius soli die südafrikanische Staatsbürgerschaft. In Südafrika beinhaltet dieser Anspruch des Kindes auf die Staatsbürgerschaft auch das Recht auf die südafrikanische Nationalität. Dies ergibt sich aus Art. 5 der Interimsverfassung, durch den die früher vorgenommene Trennung von Nationalität und Staatsbürgerschaft abgeschafft wurde. Aufgrund von Art. 5 Abs. 3 der Interimsverfassung sind alle südafrikanischen Staatsbürger berechtigt, den Nutzen und die Rechte, die sich aus der Staatsbürgerschaft ergeben, in Anspruch zu nehmen. Zu diesen Rechten gehören auch solche, die sich aus der Nationalitätszugehörigkeit ergeben. ${ }^{76}$ Der Schutz der Nationalität, der auch in zahlreichen internationalen Konventionen festgehalten ist, ${ }^{77}$ beruht auf dem Grundgedan-

Art. 33 endg. Verfassung „Just administrative action“; M. G. Erasmus, South African Citizenship in a Constitutional Context, unveröffentlichter Artikel, University of Stellenbosch.

President of the Republic of South Africa v Hugo 1997 (6) BCLR 708 (CC).

74

Births and Deaths Registration Act 51 von 1992.

Südafrika hat sowohl die Convention on the Rights of the Child, als auch den International Covenant on Civil and Political Rights ratifiziert; vgl hierzu J. Sloth-Nielsen, Ratification of the United Nations Convention on the Right of the Child: Some Implication for South African Law, SAJHR, 1995, Vol. 11, S. 401; A. Cachalia, Fundamental Rights in a New Constitution, 1994, S. 100.

J. Dugard, International Law - A South African Perspective, 1994, S. 348 f.

77 United Nations Convention on the Reduction of Statelessness; Art. 7 Convention on the Rights of the Child; Art. 24 Abs. 3 International Covenant on Civil and Political Rights; Art. 20 Abs. 1 American Convention on Human Rights; vgl. P. Weis, Nationality and Statelessness, International Law, 1979, Vol. 2, S. 161, 169. 
ken, die Staatenlosigkeit zu reduzieren. Ziel der internationalen Abkommen ist es, jede nationale Norm unwirksam werden zu lassen, die die Staatenlosigkeit eines Kindes zur Folge hat. ${ }^{78}$ Es stellt sich folglich die Frage, ob der Staat angesichts dieser internationalen Zielsetzung und aufgrund des Wortlautes von Art. 30 Abs. 1 (a) der Interimsverfassung, wonach jedem Kind ein Recht auf einen Namen und eine Nationalität von Geburt an zusteht, verpflichtet ist, einem Kind, das ansonsten staatenlos werden würde, die südafrikanische Staatsbürgerschaft zu geben, auf die es ansonsten kein Anrecht hätte. Der Wortlaut des Art. 7 der Convention on the Rights of the Child und des Art. 24 Abs. 2 der International Covenant on Civil and Political Rights spricht von dem Recht, eine Nationalität zu erwerben (,acquire“). Demnach kann ein Kind die Nationalität des Landes, in dem es geboren wird, annehmen, selbst wenn die Eltern illegal eingewandert sind. ${ }^{79}$ Der Staat soll jedoch sicherstellen, daß die Erteilung der Staatsbürgerschaft mit den nationalen Gesetzen im Einklang steht. In Übereinstimmung hiermit garantiert § 2 Abs. 1 (4) (i) South African Citizenship Act von 1995 ein Recht auf Nationalität simpliciter. Danach muß ein Kind für die Erlangung der Staatsbürgerschaft keine weiteren Voraussetzungen erfüllen. ${ }^{80}$

Art. 5 Abs. 2 der Interimsverfassung bestimmt, daß das südafrikanische Parlament ein Gesetz zur Regelung der Staatsbürgerschaft erlassen muß. Demnach könnte Art. 5 Abs. 2 eine Qualifizierung zu Art. 30 Abs. 1 (a) darstellen, was zur Folge hätte, daß Erwachsene und Kinder gleich behandelt werden müßten und somit die Effizienz von Art. 30 Abs. 1 (a) beschränkt werden würde. Art. 30 Abs. 1 (a) könnte aber auch eine Ausnahme zu Art 5 Abs. 2 darstellen, indem er besondere Regelungen für die drohende Staatenlosigkeit eines Kindes trifft. Hierfür könnte die größere Gefährdung und Verletzlichkeit von Kindern sprechen. Bei dieser Auslegung würde jedoch § 10 South African Citizenship Act von 1995 verfassungswidrig sein. Dieser besagt, daß ein Kind die Staatsbürgerschaft verliert, wenn es außerhalb der Republik Südafrika geboren wurde und seine Eltern die südafrikanische Staatsbürgerschaft verlieren. In diesem Fall könnte das Kind jedoch staatenlos werden. ${ }^{81}$

\section{Der South African Citizenship Act von 1995}

Im Hinblick auf Art. 5 Abs. 2 der Interimsverfassung ${ }^{82}$ war die südafrikanische Regierung verpflichtet, ein Gesetz zu erlassen, das die Annahme, den Verlust und die Erneuerung der

A. Pappas, Law and the Status of the Child, Columbia HRLR, 1981, Vol. 13, Introduction.

D. Hodgson, The Child's Right to Legal Identity, Australian JFL, 1993, Vol. 7, S. 121, 125.

81

A. Pantazis, Children's Rights, in: Chaskalson et al., Constitutional Law of South Africa, 1996, Kap. 33, S. 2.

82 Ibid, S.3.

Art 5 Abs. 2 Interimsverfassung entspricht im wesentlichen Art. 3 Abs. 3 endg. Verfassung, s. Fn. 70 . 
Staatsbürgerschaft vorsieht. Mit dem daraufhin im Oktober 1995 erlassenen South African Citizenship Act (im folgenden SACA 95) ${ }^{83}$ traten verschiedene Änderungen der bis dahin geltenden Staatsbürgerschaftsgesetze in Kraft, die das Ziel verfolgen, das Staatsbürgerschaftsrecht verfassungskonform zu gestalten.

\section{a) Eine einheitliche Staatsbürgerschaft}

Wichtigstes Ziel, das mit dem SACA 95 angestrebt wurde, war die Vereinigung der Staatsbürgerschaftsgesetze Südafrikas und der Homelands. Noch in der Interimsverfassung von 1994 war die weitgehende Gültigkeit der Staatsbürgerschaftsgesetze Südafrikas und der vier unabhängigen Homelands bestätigt worden. ${ }^{84}$ Doch bereits im gleichen Jahr erklärte der am 27. April 1994 designierte Innenminister, Buthelezi, daß eine Änderung der Gesetzeslage dringend erforderlich sei, um die wegen der verschiedenen Staatsbürgerschaftsgesetze bestehende Rechtsunsicherheit zu beseitigen. ${ }^{85}$ Mit dem Inkrafttreten des für die gesamte Republik Südafrika nunmehr geltenden SACA 95 wurden die Staatsbürgerschaftsgesetze der Homelands, und mit ihnen 21 weitere Gesetze, aufgehoben. ${ }^{86}$

Das Gesetz war ein wichtiger Meilenstein bei der Aufhebung früherer Apartheidgesetze und dem Weg zur Verfassungsmäßigkeit des Staatsbürgerschaftsrechts. Das Parlament ging in der verabschiedeten Fassung des South African Citizenship Acts von 1995 sogar noch über den vom Innenminister eingebrachten Gesetzesentwurf hinaus. Dieser sah vor, daß Personen, die durch Einbürgerung die Staatsbürgerschaft der Homelands angenommen hatten, erneut ein Einbürgerungsverfahren zu durchlaufen hätten, um Bürger des vereinigten Südafrikas zu werden. Das südafrikanische Parlament hielt diese Regelung jedoch für verfassungswidrig. Das Gesetz von 1995 sah daher ein zweites Einbürgerungsverfahren für bereits in die Homelands eingebürgerte Personen nicht mehr vor, sondern verlieh ihnen automatisch die südafrikanische Staatsbürgerschaft. Der Innenminister warnte jedoch vor dieser Regelung. Zwar könne die südafrikanische Staatsbürgerschaft, die durch Betrug, falsche Angaben oder Verheimlichung von Tatsachen im Einbürgerungsverfahren erworben worden sei, auch wieder aufgrund des SACA 95 entzogen werden. Ein Entzug der Staatsbürgerschaft sei jedoch erheblich erschwert, wenn die Staatsbürgerschaft bereits in einem Homeland durch falsche Angaben oder Verheimlichung von Tatsachen erworben worden

Art. 229 Interimsverfassung.

85 South Africa; Debates of the National Assembly, cols. 4315, 4320, 14. September 1995. Im Sinne des Verfassungsauftrags einer Regierung der vereinigten Republik, besetzen die „kleinen“ Parteien, wie z.B. die IFP, mehrere Ministerposten. 
sei, denn in einem ,,automatisierten“ Einbürgerungsverfahren könnten solche Verstöße nur noch äußerst schwer aufgedeckt werden. ${ }^{87}$

Darüber hinaus wurden noch weitere vom Innenminister eingebrachte Vorschläge wegen des Vorwurfs der Verfassungswidrigkeit vom Parlament abgelehnt. Hierunter fiel u.a. die im Ermessen des Ministers stehende Möglichkeit, die Staatsbürgerschaft solchen Südafrikanern zu entziehen, die länger als sieben Jahre im Ausland gelebt hatten. Nicht abgelehnt wurden hingegen Regelungen, die eine Ausweitung des Staatsbürgerschaftsrechts mit sich brachten, wie z.B. die Vergabe der Staatsbürgerschaft an staatenlose, in Südafrika geborene Personen ${ }^{88}$ oder die Eröffnung des Gerichtsweges gegenüber jeder vom Innenminister erlassenen Entscheidung im Sinne des SACA $95 .{ }^{89}$

\section{b) Erwerb der Staatsbürgerschaft}

Kapitel 2 des Citizenship Acts bestimmt drei Arten für den Erwerb der südafrikanischen Staatsbürgerschaft. Diese kann durch Geburt in Südafrika, durch Abstammung von südafrikanischen Eltern oder durch Einbürgerung erlangt werden. Im Gegensatz zum Citizenship Act von 1949 und dessen Restoration of South African Citizenship Act von 1986 wurde von der südafrikanischen Regierung mit dem Citizenship Act von 1995 eine schnelle und unkomplizierte Vergabe der Staatsbürgerschaft angestrebt. Primär zielte dieses Bestreben auf die Eingliederung der Bürger der TBVC-Staaten. ${ }^{90}$

Die Staatsbürgerschaft durch Geburt erwirbt, wer nach Erlaß des SACA 95 innerhalb der Republik Südafrikas geboren wird. Dies gilt jedoch nicht für Kinder illegaler Einwanderer, es sei denn, die Kinder würden staatenlos oder von südafrikanischen Staatsbürgern adoptiert werden. Ferner erlangt die Staatsbürgerschaft durch Geburt, wer bereits vor Erlaß des Gesetzes südafrikanischer Staatsbürger aufgrund von Geburt gewesen war oder nach Oktober 1995 außerhalb der Republik als Kind südafrikanischen Staatsbürger, die für ein südafrikanisches Unternehmen oder die Regierung arbeiten, geboren wird. ${ }^{9}$

Entsprechende Regelungen gelten für die Erteilung der Staatsbürgerschaft aufgrund familiärer Abstammung. Jeder, der bereits vor Erlaß des Gesetzes Staatsbürger aufgrund seiner

87

88

89

90

J. Klaaren, Recent Citizenship in South Africa, 1998, http://www.law.wits.ac.za/docs/saca3.htm,

S. 4.

91

South Africa, Debates of the Senate, col. 2609, 7. September 1995.

$\S 2$ Abs. 4 b) (i) SACA 95.

$\S 25$ SACA 95.

$\S 2$ SACA 95 . 
Abstammung war, behält diese. All diejenigen, die nach Erlaß des SACA 95 außerhalb der Republik Südafrika geboren werden, erwerben die Staatsbürgerschaft, wenn ihre Eltern Südafrikaner sind und sie die Geburt ihres Kindes bei dem zuständigen südafrikanischen Konsulat anmelden. ${ }^{92}$

Für die Erlangung der Staatsbürgerschaft im Wege des Einbürgerungsverfahrens sieht der Citizenship Act von 1995 wesentliche Änderungen gegenüber den oben genannten älteren Staatsbürgerschaftsgesetzen vor. ${ }^{93}$ Ersatzlos gestrichen wurde die Regelung, die eine direkte Einbürgerung nach einer Aufenthaltszeit von fünf Jahren aufgrund einer Daueraufenthaltsgenehmigung vorsah. Diese Regelung hatte seit 1978 die Rekrutierung weißer Soldaten aus dem Ausland attraktiver gestalten sollen. ${ }^{94}$ Umstritten war die Vergabe der Staatsbürgerschaft an eingebürgerte Homelandbürger. § 4 Abs. 1 (a) (iii) SACA 95 sieht für diese Personen die Vergabe der Staatsbürgerschaft im Wege der Einbürgerung vor. Um diesen Menschen jedoch kein zweites Einbürgerungsverfahren zuzumuten, wurde auf die Durchführung eines solchen Verfahrens verzichtet, wenn diese nachweisen konnten, daß das entsprechende Einbürgerungsverfahren für ein Homeland durchgeführt worden war. ${ }^{95}$ Neben diesen Änderungen wurde auch der Ermessensspielraum des Innenministers eingeschränkt, der bis zu diesem Zeitpunkt darin bestanden hatte, von den Voraussetzungen der vorgeschriebenen Einbürgerungszeit von vier Jahren und von der des Sprechens einer Landessprache abweichen zu können. Begründet wurde die Einschränkung des Ermessensspielraumes durch den Senat mit der Gefahr der Korruption, die bestünde, wenn einem Minister ein zu weiter Ermessensspielraum zustehe. ${ }^{96}$ Bereits 1997 wurde diese Einschränkung des Ermessens jedoch mit der Maßgabe einer jährlichen Überprüfung der Ausnahmegenehmigungen wieder aufgehoben. ${ }^{97}$

Ein Antragsteller muß zur Einbürgerung eine Vielzahl von Voraussetzungen erfüllen. Er muß eine Daueraufenthaltsgenehmigung für die Republik besitzen, dort dauerhaft und mindestens vier Jahre vor der Einbürgerung gewohnt haben, von gutem Charakter sein, weiterhin anstreben, in Südafrika zu leben, eine der offiziellen Landesprachen ${ }^{98}$ sprechen und Kenntnisse über die Rechte und Pflichten eines südafrikanischen Staatsbürgers besit-

92

93

94

95

96

97

98

\section{§ 3 SACA 95}

$\S 4$ SACA 95.

Memorandum on the Objects of the South African Citizenship Bill, Government of the Republic of South Africa, 1995, B 23 - 95, Rz. 3. 2.

Vgl. Diskussion unter 5. a).

Senator Lamani (ANC), South Africa, Debates of the Senate, cols. 2612, 7. September 1995.

§ 4 South African Citizenship Amendment Act 69 von 1997.

Art. 6 Abs. 1 endg. Verfassung, Offizielle Sprachen: Sepedi, Sesotho, Setswana, siSwati, Tshivenda, Xitsonga, Afrikaans, Englisch, isiNdebele, isiXhosa und isiZulu. 
zen. ${ }^{99}$ Neben diesen persönlichen Voraussetzungen muß der Antragsteller auch einen Eid auf die südafrikanische Staatsbürgerschaft ablegen. Diese Pflicht bestand bereits vor Erlaß des SACA 95. Der South African Citizenship Act von 1949 sah vor, daß alle Einwanderer, die das dreizehnte Lebensjahr vollendet hatten, folgenden Eid sprechen mußten:

„I, (...), do hereby declare on oath that I will be faithful to the Republic of South Africa, observe its laws, promote all that which will advance it and oppose all that may harm it. So Help Me God.“100

In der ersten Gesetzesvorlage zum South African Citizenship Act 1995 wurde ein sehr ausführlicher Eidestext vorgeschlagen. ${ }^{101}$ Durch diesen ausführlichen Text sollten das Ereignis der Einbürgerung und die Pflichten, Rechte und Aufgaben eines südafrikanischen Staatsbürgers hervorgehoben werden. ${ }^{102}$ Letztlich entschied sich der Senat jedoch für eine kurze Eidesformel:

„I, (...), do hereby solemnly declare that I will be loyal to the Republic of South Africa, promote all that will advance it and oppose all that may harm it, uphold and respect its Constitution and commit myself to the furtherance of the ideals and principles contained therein." 103

Im Gegensatz zur ersten Gesetzesvorlage ${ }^{104}$ enthält der nunmehr angenommene Eidestext mehr unbestimmte Begriffe, die die Rechte und Pflichten umschreiben, die sich aus der Verfassung ergeben und die ein Staatsbürger zu befolgen hat. Der Text ist im Vergleich zum ersten Vorschlag positiver formuliert. Ihm liegt nicht mehr der gesetzestextliche Unterton zugrunde, den der Katalog von Staatsbürgerpflichten der Gesetzesvorlage mit sich

99

§ 5 Abs. 1 SACA 95.

100 Anhang, South African Citizenship Act von 1949

101 Entwurf zum South African Citizenship Bill von 1995: „I,..., do hereby solemnly declare that I will be faithful to the Republic of South Africa, and I hereby undertake to carry out my duties as a South African citizen to the best on my abilities. I especially commit myself to - obeying the laws of my country; exercising the franchise to ensure that my country's affairs rest in good hands; defending my country; paying such taxes may be believed; assisting in the preservation of the natural beauty of my country and to conserving its soil; developing my physical, intellectual and social capacities so that I shall be an asset to my country and its people; being tolerant towards my fellow citizens and to fostering good relations. I also declare that I am fully aware of my rights and privileges as a citizen of South Africa, and I commit myself to exercising those rights and privileges in such a manner that I will promote the common weal in my country, and oppose all that may harm my country and my fellow citizens."

102

Memorandum on the Objects of the South African Citizenship Bill, 1995, § 9, Rz. B 23 - 95.

104

1. Anhang, South African Citizenship Act von 1995.

Vgl. Fn. 101. 
brachte. ${ }^{105}$ Im Vergleich zum Eid von 1949 stehen die Verfassung und die Grundrechte im Vordergrund. Außerdem wurde auf den religiösen Zusatz verzichtet. Dies überrascht, da in der Präambel zur Verfassung noch ausschließlich der Schutz Gottes für das gesamte südafrikanische Volk in sieben der elf Nationalsprachen eingefügt worden war und dies trotz der Vielzahl der in Südafrika gelebten Religionen. Genau wie der Eidestext von 1949 beinhaltet auch der Eid von 1995 keine Formulierung über den Verzicht auf eine frühere Staatsbürgerschaft. Dies wird als eine Offerte an eine doppelte Staatsbürgerschaft gesehen, soweit dies mit der Treue zu Südafrika vereinbar ist. ${ }^{106}$

c)

\section{Verlust der südafrikanischen Staatsbürgerschaft}

Der Verlust der südafrikanischen Staatsbürgerschaft kann durch freiwillige Aufgabe oder Entziehung erfolgen. Die Aufgabe erfolgt durch eine Erklärung des Bürgers. Sie enthält die Auskunft über die Annahme der Staatsbürgerschaft eines anderen Landes unter gleichzeitiger freiwilliger Aufgabe der südafrikanischen Staatsbürgerschaft. ${ }^{107}$ Die Entziehung der Staatsbürgerschaft unterteilt der Gesetzgeber in den Verlust und die Entziehung der Staatsbürgerschaft. Der Verlust soll erfolgen, wenn der Bürger freiwillig durch einen formalen Akt mit Ausnahme der Heirat die Staatsbürgerschaft eines anderen Landes annimmt oder, wenn er die Staatsbürgerschaft eines anderen Landes bereits besitzt und für dieses gegen die Republik Südafrika kämpft. ${ }^{108}$ Entzogen werden kann die südafrikanische Staatsbürgerschaft einem Bürger, wenn festgestellt wird, daß diese aufgrund von falschen Angaben im Rahmen des Einbürgerungsverfahrens erworben worden war. Die Entscheidung hierüber steht im Ermessen des Innenministers. Die Entziehung der Staatsbürgerschaft ist auch möglich, wenn jemand mit einer doppelten Staatsbürgerschaft zu einer Freiheitsstrafe von mehr als einem Jahr verurteilt worden ist, oder die Entziehung im öffentlichen Interesse steht. ${ }^{109}$ Schließlich kann bei Bestehen einer doppelten Staatsbürgerschaft die südafrikanische entzogen werden, wenn der Bürger die Staatsbürgerschaft des anderen Landes oder dessen Paß gebraucht. ${ }^{110}$ Die Auslegungsprobleme, die sich durch den Begriff „Gebrau-

105

J. Klaaren, Post Apartheid Citizenship in South Africa, 1999, http://www.law.wits.ac.za/school/ klaaren/klaarenc.htm, S. 11.

106

J. Klaaren, Post Apartheid Citizenship in South Africa, 1999, http://www.law.wits.ac.za/school/ klaaren/klaarenc.htm, S. 11.

107 § 7 SACA 95.

108 § 6 SACA 95.

109 § 8 SACA 95.

110 § 9 SACA 95: „The Minister may by order deprive a South African citizen of his or her South African citizenship if he or she also has the citizenship or nationality of another country, and has at any time made use of the franchise or the passport facilities of that country or performed such 
chen" ergeben, sind vielfach diskutiert worden. Dem liegt zugrunde, daß dieser Entziehungsgrund bereits in den früheren Staatsbürgerschaftsgesetzen vorgesehen und dort nicht eindeutig definiert worden war. Zur Zeit der Apartheid war der Begriff daher immer wieder politisch ausgelegt worden, mit der Folge, daß Privilegierten die doppelte Staatsbürgerschaft erhalten blieb, während sie anderen um so schneller entzogen worden war. ${ }^{111}$ Der Begriff des „Gebrauchmachens“ ist daher durch das Gesetz von 1995 beschränkt worden, und zwar auf die Ausübung des Wahlrechts in dem anderen Land, und auf die Nutzung des nämlichen Passes. ${ }^{112}$

Die Diskussion um die doppelte Staatsbürgerschaft und die Entziehung der südafrikanischen Staatsbürgerschaft im Fall des Gebrauchens der fremden Staatsbürgerschaft, verdeutlicht das Bestreben, Gesetzesformulierungen und Auslegungen $\mathrm{zu}$ finden, die der neuen Politik der Toleranz entsprechen und die zugleich einem Mißbrauch der doppelten Staatsbürgerschaft entgegentreten.

Der Innenminister Buthelezi sagte während des Gesetzgebungsverfahrens hierzu: „Obwohl der Regierung die Argumente für und gegen eine doppelte Staatsbürgerschaft bewußt waren, sah sie keine Veranlassung, die doppelte Staatsbürgerschaft abzuschaffen. Ich bin mir sicher, daß die Mehrheit der Südafrikaner, die eine doppelte Staatsbürgerschaft besitzen, ebenso loyal und treu gegenüber der Republik und der Verfassung sind wie ausschließlich südafrikanische Staatsbürger. Der Gesetzesentwurf enthält keine Regelungen, die von der gegenwärtigen Politik der Toleranz abweichen. Gegenwärtig steht dem Minister das Recht zu, jemandem, der eine doppelte Staatsbürgerschaft besitzt, die südafrikanische zu entziehen, wenn er die Staatsbürgerschaft des anderen Landes gebraucht. Der Gesetzesentwurf enthält eine ähnliche Regelung, aber er weicht insofern von der jetzigen Regelung ab, als daß nunmehr der Gebrauch des Passes oder die Wahlteilnahme in dem anderen Land als konkretisierte Beispiele eines Gebrauchens in das Gesetz aufgenommen wurden. Gegenwärtig kann Personen mit einer doppelten Staatsbürgerschaft der Gebrauch des ausländischen Passes genehmigt werden, wenn dies im voraus beantragt wurde, und wir wer-

other voluntary act which, to the satisfaction of the Minister, indicates that such citizen has made use of the citizenship or nationality of that other country."

J. Klaaren, Recent Citizenship in South Africa, 10. Mai 1998, http://www.law.wits.ac.za/docs/ saca3.hatm, S. 3.

112

Die Diskussion muß jedoch im Licht der verwaltungsrechtlichen Handhabe gesehen werden. Die Zahl der Entziehungen der Staatsbürgerschaften aufgrund des Gebrauchs des ausländischen Passes ist sehr klein. 1995 wurde z.B. 533 Personen die Staatsbürgerschaft entzogen. Bei drei eingebürgerten Staatsbürgern geschah dies aufgrund der Anweisung durch den Minister im Rahmen des öffentlichen Interesses und in zehn Fällen lebten die Personen außerhalb Südafrikas. Keiner der Personen wurde die Staatsbürgerschaft aufgrund von § 9 SACA entzogen. Dem größten Teil wurde wegen falscher Angaben bei der Einbürgerung die Staatsbürgerschaft wieder entzogen. South Africa, Department of Home Affairs, 1995, Annual Report, S. 12. 
den an dieser Praxis festhalten, wenn dieser Gesetzesentwurf verabschiedet wird. “113 ${ }^{113}$ Sikakane vom African National Congress (ANC) erklärte dazu, daß es zu diesem Zeitpunkt nicht das Ziel der südafrikanischen Politik sei, die doppelte Staatsbürgerschaft aufzugeben, vielmehr wäre dies sogar nachteilig. Er kritisierte aber, daß die Frage der Loyalität gegenüber Südafrika nicht ausreichend bestimmt sei. ${ }^{114}$ Dem widersprach jedoch die FreedomFront, die in der Vorschrift eine Festigung der Loyalitätspflicht gegenüber Südafrika sah. Sie begrüßte die Vorschrift als eine weitgehende Beschränkung der doppelten Staatsbürgerschaft. Dies sei nach ihrer Auffassung auch notwendig, da der Gebrauch einer anderen Staatsbürgerschaft die südafrikanische in jedem Fall gefährde. ${ }^{115}$ Der Sprecher des Senatskomitees beendete die Debatte mit einem Plädoyer für eine tolerante doppelte Staatsbürgerschaft. Cwele (ANC) sagte: „Das Gesetz toleriert die doppelte Staatsbürgerschaft. Aber es beinhaltet auch einige Beschränkungen, die notwendig sind, um die Treue eines betroffenen Staatsbürgers zu diesem Land, zu der Verfassung und der Souveränität unserer Nation nicht zu untergraben. " Cwele bezog sich in der Diskussion auf die Situation vieler weißer Staatsbürger ${ }^{116}$, aber auch auf die Situation von schwarzen Bürgern, die im Exil gelebt hatten. Zur Zeit der Reformbewegung und der Diskussion über die Beibehaltung der Apartheidspolitik waren Weiße, die eine Daueraufenthaltsgenehmigung besaßen, stets ermutigt worden, die südafrikanische Staatsbürgerschaft anzunehmen. Dabei war ihnen der Erhalt ihrer alten Staatsbürgerschaft zugesichert worden. Nach der Wende standen auch Schwarze, die im Exil gelebt hatten, vor der Frage der Staatsangehörigkeit, denn einige Mitglieder der Freiheitsbewegung hatten die Staatsbürgerschaft ihres Exillandes angenommen. ${ }^{117}$

Neben den grundsätzlichen Erwägungen, die für die Beibehaltung der doppelten Staatsbürgerschaft sprachen, erwähnte der Sprecher des Senatskomitees aber auch die Notwendigkeit der Entziehung der Staatsbürgerschaft für den Fall des Gebrauchmachens von einem fremden Paß oder der Teilnahme an der Wahl in einem anderen Land. Die Entziehung der südafrikanischen Staatsbürgerschaft in diesen Fällen sei notwendig, um Personen mit einer doppelten Staatsbürgerschaft davon abzuhalten, die Souveränität der südafrikanischen Republik zu untergraben. Außerdem wies Cwele darauf hin, daß Personen, die in mehreren

South Africa, Debates of the National Assembly, col. 4316, 14. September 1995.

114

South Africa, Debates of the National Assembly, col. 4319, 14. September 1995.

115 W. A. Botha, South Africa, Debates of the National Assembly, col. 4322, 14. September 1995.

116

Auch Buthelezi ging noch einmal auf die Situation ein: "Viele erkennen nicht, daß es zu einer erheblichen Destabilisierung unseres Landes führen würde, wenn eine doppelte Staatsbürgerschaft entzogen werden würde, besonders, da mehr als eine Millionen englisch sprechende (weiße) Südafrikaner in diesem Land die doppelte Staatsbürgerschaft besitzen. In dieser Übergangszeit, in der sich unser Land gerade befindet, werden sicherlich viele Personen, die eine doppelte Staatsbürgerschaft besitzen, dieses Land verlassen. Das ist aber nicht im Interesse unseres Landes." Debates of 117 the National Assembly, cols. 4324, 4325, 14. September 1995.

Debates of the Senate, col. 2620, 7. September 1995. 
Ländern wählen, die politische Ordnung zwischen diesen Ländern beeinflussen und auf diese Weise die Unabhängigkeit des Staates gefährden. ${ }^{118}$

\section{Schlußfolgerung}

Die Ziele, die sich die südafrikanische Regierung im Rahmen der Neuordnung des Staatsbürgerschaftsrechts gesetzt hatte, sind weitgehend erreicht worden. Die zur Zeit des Apartheidregimes in die Homelands ausgebürgerten schwarzen Bevölkerungsteile wurden noch zur ersten freien und gemeinsamen Wahl am 27. April 1994 wieder in die Republik Südafrika integriert. Gleichzeitig wurden auch die TBVC-Staaten aufgelöst und mit Südafrika vereint. Mit der Aufhebung der Trennung zwischen Nationalität und Staatsbürgerschaft erlangten die ehemaligen Bürger der Homelands, die schon immer die südafrikanische Nationalität besessen hatten, einen Anspruch auf die südafrikanische Staatsbürgerschaft. Dieser Anspruch wurde bereits 1993 im Restoration and Extension of South African Citizenship Act umgesetzt, der die Vergabe der Staatsbürgerschaft an die Homelandbewohner direkt oder im Wege eines Einbürgerungsverfahrens vorsah. Diese Entwicklung ging einher mit dem Inkrafttreten der Übergangsverfassung im Jahr 1994. In ihr wurde der für die Jahrzehnte unterdrückte schwarze Bevölkerung wesentliche Gleichheitsgrundsatz und die ebenso wichtigen politischen Rechte verankert. Wesentlichen Einfluß auf die Einführung von Menschen- und Bürgerrechten hatten auch die nunmehr umgesetzten internationalen Menschenrechtsabkommen. Sie sicherten die Rechte der Staatenlosen und Minderheiten in Südafrika ab.

Mit dem SACA 95 erließ die südafrikanische Regierung ein Staatsbürgerschaftsgesetz, das die Vergabe der Staatsbürgerschaft auf der Grundlage der Verfassung und der internationalen Menschenrechte zum Inhalt hat. In Übereinstimmung mit der Vergangenheit nimmt der Grundsatz des ius soli den wichtigsten Platz im neuen Staatsbürgerschaftsrecht ein. Daneben steht das ius sanguinis und die Vergabe der Staatsbürgerschaft durch Einbürgerung. Das Gesetz regelt ferner die Voraussetzungen zur Entziehung der Staatsbürgerschaft sowie deren Folgen. Die Formulierungen der Staatsbürgerschaftsgesetze zur Zeit der Apartheid, die zur Durchsetzung der Rassentrennungspolitik oftmals willkürlich ausgelegt worden waren, sind in den SACA 95 nicht aufgenommen worden. Ein Beispiel hierfür bietet die Entziehung der Staatsbürgerschaft bei Vorliegen einer doppelten Staatsbürgerschaft und des Gebrauchens der fremden Staatsbürgerschaft. Wann ein „Gebrauchmachen“ vorliegt, wurde genau definiert. Die Auslegung des Begriffes liegt nicht mehr im Ermessen des Innenministers, sondern ist an die Ausübung des Wahlrechts oder die Benutzung des Passes eines anderen Landes geknüpft. Eine wesentliche Änderung bestand ferner in der Eröffnung des Rechtsweges gegen Entscheidungen des Innenministers. Im Gegensatz zum 
Staatsbürgerschaftsrecht zur Zeit der Apartheid, das keine Rechtsmittel gegen die Entscheidung des Innenministeriums zur Vergabe oder Entziehung des Staatsbürgerschaftsrechts vorsah, kann sich nunmehr jeder gegen eine für ihn nachteilige Entscheidung an die südafrikanischen Gerichte wenden.

Die Einführung einer einheitlichen und anti-rassistischen Demokratie und der damit verbundenen Einführung einer starken südafrikanischen Staatsbürgerschaft zielte auf die Wiedervereinigung Südafrikas mit den Homelands und die Einbürgerung ihrer Bewohner im Rahmen einer Politik der Toleranz. Der Zusammenschluß führte dazu, daß sich Südafrikas Bevölkerung mit den Bewohnern der TBVC-Staaten durchmischte. Die Aufnahme der Homelandbewohner hatte zur Folge, daß sich eine gewissen Intoleranz gegenüber Ausländern in Südafrika ausbreitete. Dieses, zumeist auf sozialen Ängsten der Bevölkerung beruhende gespannte Verhältnis zu Ausländern, prägte in der Zeit nach der Wiedervereinigung auch die Politik des südafrikanischen Innenministeriums. Dies äußerte sich in einer Verschärfung der Voraussetzungen für die Beantragung einer Aufenthaltsgenehmigung oder einer Arbeitserlaubnis für Ausländer. Ein entsprechendes Meinungsbild setzte sich auch in der Bevölkerung durch. Umfragen zufolge machen $42 \%$ der Befragten die Öffnung des Landes und den Einlaß von Ausländern von freien Arbeitsplätzen abhängig, 27\% verlangen strikte Beschränkungen der Zahl der Einwanderer und nur 25\% unterstützen eine Politik der offenen Grenzen. ${ }^{119}$ Ebenso verhält es sich mit dem Zugang zu sozialen Einrichtungen. Die Mehrheit der südafrikanischen Bevölkerung meint, daß solche Einrichtungen ausschließlich für Südafrikaner reserviert sein sollten. ${ }^{120}$ Die Politik des südafrikanischen Innenministers hinsichtlich von Immigrationsfragen entspricht weitgehend der in der Bevölkerung bestehenden Meinung. Er begrüßt zwar, daß viele Ausländer in Südafrika investieren und ihre beruflichen Qualifikationen und Fähigkeiten mitbringen, erklärt aber gleichzeitig, daß illegale Einwanderer keinen Zugang zu sozialen Einrichtungen haben werden, für die der südafrikanische Steuerzahler aufkommt. ${ }^{121} \mathrm{Im}$ Gegensatz zu den laut Umfragen bestehenden Befürchtungen erwarten in Südafrika lebende Ausländer nicht notwendigerweise freien Zugang zu sozialen Einrichtungen. Vielmehr sind sie weitgehend bereit, für diese zu zahlen. Erwartet wird jedoch, daß ihnen eine Arbeitsmöglichkeit, der Schulbesuch, medizinische Hilfe und eine Wohnung nicht vorenthalten werden. Von diesen wirtschaftlich-sozialen Rechten werden die politischen Rechte unterschieden. Zwar wird von der Mehrheit der Ausländer das Recht, eine Daueraufenthaltsgenehmigung und darüber

D. McDonald /L. Mashike / C. Golden, The Lives and Times of African Migrants and Immigrants in Post-Apartheid South Africa, South African Migration Project, 1999, S. 27.

D. M. Taylor / R. Mattes / D. McDonald / A. Poore / W. Richmond, Still Waiting for the Barbarians: South African Attitudes to Immigrants and Immigration, South African Migration Project, 1999, S. 12.

121

Sowetan, 30. April und 7. Mai 1997. 
hinaus die südafrikanische Staatsbürgerschaft erwerben zu können, gefordert. Doch erwarten sie nicht, an südafrikanischen Wahlen teilnehmen zu dürfen. ${ }^{122}$ in Post-Apartheid South Africa, South African Migration Project, 1999, S. 25. 